\title{
CARE AND ATTENTION
}

\author{
S.L. Sevenhuijsen \\ Retired Professor of Women's and Gender Studies, Social Sciences \\ Utrecht University \\ Netherlands \\ e-mail: selma@selmasevenhuijsen.nl
}

\section{ABSTRACT}

Attention is an important aspect of care in both public and private realms, including the higher education context. Attention is a normative concept, which is embedded in caring practices. Attentiveness or attention the first element of interconnected phases of care and pertains to "caring about", or perceiving the need for care, which initiates the caring process. This article introduces the notion of "active attention" and "attentive activities" as an ideal image of attention enabling the practice of good care.

Keywords: care, attention, active attention, attentive activities, waiting

"Love is the capacity to take care, to protect, to nourish. If you are not capable of generating that kind of energy toward yourself - if you are not capable of taking care of yourself, of nourishing yourself, of protecting yourself - it is very difficult to take care of another person. In the Buddhist teaching, it's clear that to love oneself is the foundation of the love of other people. Love is a practice. Love is truly a practice." (Thich Nhat Hanh https://plumvillage.org)

\section{INTRODUCTION}

In the last decade, attentiveness and attention have been increasingly foregrounded as crucial moral elements by theorists who subscribe to relational ontologies in various fields (see for example Barad 2007; Despret 2015; Haraway 2016; Rose 2013). The contribution of attention and attentiveness to scholarly and pedagogical practices have also been highlighted in higher education (see for example Boulous Walker 2016; Bozalek 2017; Bozalek and Zembylas 2017; Lenz Taguchi 2012). This article builds on this growing interest in attentiveness and attention in practices and policies of higher education.

The care of parents for their children starts with the attention for their needs for shelter, food, education and love. A lack of adequate attention from parents can leave marks that last a lifetime. Care for the sick and the dependent elderly thrives on the provision of daily attention. Friendships and love relations between adults would be quite unthinkable without attention. And it is not just in daily life that attention is relevant, it is also a topic with political implications. Citizens expect attention from their political representatives who have the task to come up for 
their needs. The absence of attention can lead to serious forms of "privileged irresponsibility" a term coined by Joan Tronto to denote practices in which powerful persons can deny the hardships of others and the care they receive of people around them. In fact, nearly all walks of life are shaped by a "politics of need interpretation" that influences how persons can build a decent life for themselves and those who are dependent on them. Much depends upon how attentive these politics are.

In the ethic of care attention has received a prominent place. Joan Tronto built her theory of care on the statement that "to be a morally good person requires, amongst others, to meet the demands of caring that present themselves in his or her life". This thrives on the ability to be attentive for the needs for care. Tronto proposed to see care as a process existing of four interconnected phases or elements, each associated with a key moral category. Attention figures prominently here. The first phase is caring about, perceiving the need for care, with attentiveness as its core "moral moment". The second is taking care of, taking concrete steps that care gets started, with responsibility as the crucial moral attitude. The third phase is caregiving, the actual hands-on work of care, with competence as main moral notion. The final is care receiving with responsiveness as moral guideline.

So in this approach attention belongs to the first phase of care, it is the value and the attitude that initiates the caring process. In what follows I will try to substantiate the notion of attention, starting from my earlier proposals that both care and attention are inherently normative concepts, embedded in caring practices (Sevenhuijsen 1998). With this I mean that the care ethic is aimed at enabling practices of good care by providing the intellectual tools for these practices to grow. In this spirit I will offer you an ideal image of attention, some ideas about attention at its best, a practice that I characterize as "active attention".

\section{ACTIVE ATTENTION}

Beyond ideas of right and wrong there is a field. I will meet you there (The Essential Rumi 1995). This is the first, wildest, wisest thing I know:

the soul exists. it is built entirely out of attentiveness (Mary Oliver http://www.kimtackett.com/ the-summer-day-poems-by-mary-oliver/).

I want to start my elaboration of "active attention" with a story. Some months ago I was telling my eight year old granddaughter that I was going to give a public talk about attention, and I asked her if she understood what attention actually is. Without hesitation she said: "that's what you are giving me when you are playing or going out with me". Bright girl as she is she exactly hit the 
point. She told me that the doing - the playing and going out - is intertwined with something else - me giving her something more. And she acknowledged that attention is a gift. Young as she is, she was obviously not competent yet to find the right words to describe this "something". But in the way she said it, she expressed her appreciation, as if she felt that this "something" assists her to learn and to grow. And for me her observation felt as a huge recognition from her side of the nature of our relationship.

Without being aware she expressed quite neatly what care ethicists have always emphasized: care is characterized by its purpose and by the intention with which it is provided. The British sociologist Marian Barnes (2012) has captured this nicely in her summary of the ethic of care: "care consists in the being attentive to needs and taking responsibility for making sure that these needs are met in order to enable people to flourish". This builds on the observation by Joan Tronto that care is a practice that can be recognised by its "nested ends". So let us start our explorations about the meaning of attention by seeing if we can find the appropriate words to further describe the "something" mentioned by my granddaughter. The quote of Marian Barnes (2012) can point the way. It clarifies that attention and intention are connected. Attention is an activity that is aimed at human flourishing.

It might seem that attention is primarily an other-regarding activity, something that we give to others. I argue that we have to take a different starting point. Practising active attention starts with our self, with a willingness to reflect on our own actions and reactions, with the intention to improve the quality of our caring interactions with others. So what is this self-activity that active attention consists of?

It is always useful to take a look at the etymological meaning of the concepts we use. Attention comes from the Latin term attendere, which gives it a double meaning. Attendere means both waiting and holding. The "waiting" dimension of attention is actually crucial. It refers to the need to suspend one's own suppositions, images and preoccupations when engaging in a caring interaction. In order to attend well to the other, I have to suspend and hold back my own feelings, associations, and fixed ideas, and to acknowledge the otherness of the other. Maybe it is comparable to "conscious witnessing", or the art of discernment.

By engaging in the practice of "waiting" I can begin to see the other as she or he really is and could be. It enables me to see both the actual situation and the potential of the other. In this way the second dimension of attention, the holding, can get started: by seeing the other as she is, I can start to think about how to "hold" her in my care. ${ }^{1}$ In Moral Boundaries Joan Tronto (1993) summarized this as follows: “One needs, in a sense, to suspend one's own goals, ambitions, plans of life, and concerns in order to recognize and to be attentive to others".

The importance of this "waiting" dimension of attention may be underscored by reflecting 
for a moment about its opposites. Let me start with an example from everyday life: many conversations tend to proceed along a path of associative thinking. Person A starts to tell something about herself to person B. Person B reacts by telling a comparable story about her or his life. Within a split second the focus of attention has shifted from person A to person B, leaving person A with an uncomfortable feeling. That is how the non-reflective mind works: it associates and compares new information with what it knows already. And with comparison other phenomena easily enter the interaction. Important among those are projection and judgment.

Projection happens when we - usually unconsciously - see repressed and denied sides of ourselves in the other. The classical example in caring situations is the popping up of the mother archetype. People frequently project their repressed feelings of absence or rejection by the mother on others: he or she has to fill the gap, or otherwise be prepared to receive the rage for being denied the right form of attention and care. This can happen both from the position of the caregiver and the care-receiver. In fact it causes that persons easily shift positions: in many caregivers is hidden a silent potential care-receiver who looks out for attention.

In psychoanalysis these mechanisms are known as transferral and counter transferral. If we do not become aware of such projecting mechanisms, judgment easily joins in. The projecting person starts to judge people by the standards of her own experiences, needs and behaviour, without having really engaged in the needs or the perspective of the other. It can result in serious forms of $\mathrm{p} /$ maternalism and - more problematic even - indifference, neglect and rejection. In the end it can be a "stopper" of any form of communication.

So the "waiting" aspect of active attention consists first of all in taking time before engaging in over hastened or unreflected forms of need-interpretation. In order to refrain from reactions that spring from our own pre-occupations, we have to engage in self-searching and reflection about our motives in engaging with others. This is not just an occasional or short-term activity. It implies making a habit of honest searching for building a relational life that corresponds with notions of good care. In order to be able to reach out to others we must have a caring and loving relationship with ourselves, and be attentive to what is happening inside us. If we want to take care of others in an appropriate way we have to be aware of our own needs and inner wounds, and put effort into meeting and healing these.

This implies developing an active will for inner growth. This is hard work that includes the overcoming of inner barriers for change and dealing with complex - often repressed - emotions like sorrow, anger, fear, aggression and despair. During this process we are transforming soulbody-mind connections. Care for the soul is indeed crucial here, and I currently emphasize this more than in my earlier thinking on care. Not without reason the major advice of the great wisdom traditions in the history of mankind is to "know your self". 
Self-knowledge is not just something we do for our own happiness; it also has the capacity to improve interpersonal life. For me it has been most helpful to - following Carl Jung distinguish the self and the Self here. I see the Self as the inner space of stillness that we can reach by going the long road of connecting with and integrating the unconscious parts of our personalities, including our dark parts, the shadow. The Self is basically a place of connection, a space where we can connect with the deeper wisdom that everything is (inter) connected and thus also interdependent.

It is also a place of freedom and wonder. By knowing ourselves we create space for knowing the other, for meeting the other-as-(s)he is, freed from projections, illusions and false expectations. Active attention is the activity through which we bring each other into being as the persons we are meant to be, in a way that enables human flourishing. As the African philosophy of care, Ubuntu, states: we can only be persons through other persons. Attention at its best enables us to perceive and acknowledge other persons and the networks of interdependence in which we shape our lives. It provides a basis for reflection on our responsibilities to hold, sustain and nourish each other in the best possible way, according to our capacities.

In this way the intention aspect of attention can also come more to the foreground. Selfknowledge and self-reflection enable us to transform impulse and motive into thoughtful intention. Attention at its best is focussed intention, arising from the will and the capacity to direct our energy at a specific action. In the context of care focussed intention means acting from a will to contribute to human flourishing. How to further elaborate this intention will depend on the characteristics of the specific practice we engage in. In care for the elderly we will have different goals than in caring for children or for the environment. Focussing implies that we do not let ourselves get confused, or distracted from the goal of the practice we are engaged in, but that we direct our energy towards this goal in the best possible way.

\section{ATTENTIVE ACTIVITIES}

The moment one gives close attention to anything, even a blade of grass, it becomes a mysterious, awesome, indescribably magnificent world in itself (Henry Miller 1962).

Until now I have argued that attention is an activity that emanates from the self, and that is aimed at creating space for others to enter and relationship to flourish. By practicing active attention self-other relationships are being transformed, both on the intra- and interpersonal level. We have to go inside our self and see ourselves more clearly in order to see the other as she is. Active attention is a relational activity, which has the capacity to enhance the awareness of 
interdependence and to improve the quality of caring relations. By going inside ourselves we create both intra- and interpersonal space from which attention can be given to others in a conscious way. By practicing active attention, we can become aware of the "nested ends" of caring practices.

My next step is to specify in more detail what the attentive activities are that we can and maybe should engage in from this space. I will mention eight of those activities, but probably there are more. Although I present them separately they are in fact interwoven: they are the most effective when practiced in an interrelated manner. As you will note they are formulated from the perspective of the care-giver, while most of them are at the same time deeply interactive.

The first - and basic - one is presence, or being there for the other. Presence is an otherdirected attitude that supposes that we move out of ourselves, and try to be there for the other. It can consist in a verbal statement of commitment, reaching out and showing interest, but it can also be shown silently, by sitting or walking together, without words or anything else. It can also imply a gesture of the body, turning oneself towards the other, or greeting by making a gesture or by making eye contact. In all these ways we give the assurance "I am here for you, and I appreciate you as you are". We can also call it recognition.

The second one is seeing. When entering a new situation we usually receive a first impression by looking - we make a quick scan of what is going on. Simultaneously our thoughts make a first interpretation of what we see. Looking turns into an attentive activity when we are able to transform it into seeing without preconceived interpretations. By striving to see persons as they are and to understand their point of view and the predicament they are in, we hopefully come to an adequate interpretation of the situation. We can also call it discernment. Seeing implies an active, conscious effort, which distinguishes it from mere looking.

The third one is active, careful listening. Again, this can be distinguished from the more passive attitude of just opening our ears. Active listening supposes creating an inner space for understanding, by suspending the inner voices of comparison and judgment. It may suppose a thoughtful questioning of the other until both parties arrive at a shared understanding of the situation. It can also imply checking with the other the correctness of our interpretation of what he or she tries to communicate. Many examples could be added. Storytelling - and thus also active listening - creates connection, enables the persons involved to give meaning to and cope with important life events. It can bring healing to deep-seated wounds.

Careful listening is a prerequisite for thoughtful speaking, my fourth principle for active attention. It was I think the Buddha who taught the golden rule for careful speaking. Before you say something always wonder: "is it true, is it relevant, is it respectful?" It means that we have to think before we talk. We may suppose that this attitude can reduce a considerable amount of 
blockages in attentive interactions.

The fifth activity is honouring our intuition. By far not all caring interactions are characterised by verbal communication. In giving attention and seeing if there is a need for care we also have to use our intuition. Actually, the best forms of care sometimes originate in someone's split second intuition that something has to be done, like in accidents and attacks. In the context of my argument I propose to see intuition as knowledge of the heart. It comprises all those things we "know" without having an immediate substantiation available. It is a form of knowledge that something is true, because it springs from a deep source of inner wisdom, that developed through past practices into an added sense, like is the case with mothers and nurses. But intuition also may just pop up.

The sixth relevant activity is reliability. Elsewhere I have argued that trust can be seen as the oil that keeps the wheel of care going (Sevenhuijsen 1999). In care (potential) care receivers entrust things that matter to them to the activity of caregivers, in the expectation that these will handle these with competence and goodwill. Of course this is not always a conscious act, like in situations of extreme vulnerability where one has to trust blindly that this condition will be responded with goodwill and care instead of abuse, violence or exploitation. The ability of the care receiver to entrust starts with attention and intention from the side of the caregiver, for example by showing the intention to be a reliable listener, who is ready to respect and protect the will and the privacy of the care-receiver. Promising is important here.

The seventh attentive activity that I want to mention is the recognition of plurality. We engage in caring interactions as differently situated individuals, with specific life histories, cultural embeddings, opinions and psychological make-ups. Recognition of this fact is - again a guarantee against counterproductive projections of sameness. For me it is in fact one of the defining characteristics of the care ethic compared to principle ethics. Principle ethics invites us to treat the other as we would want to be treated ourselves, and thus to see the other as similar to ourselves. It may be the beginning of moral consciousness, by installing awareness that we should not hurt others but treat them well. But the care ethic goes a step further. It invites us to acknowledge the uniqueness of all living beings, and to promote human flourishing in a way that can deal with difference and otherness.

The eighth one - accountability - arises from the acknowledgment that all these activities are fragile. We easily make mistakes when engaging in them. You could say that these are searching activities, often based on trial and error. They embody a search for ways to create moral interactions that enable care to proceed as well as possible, acknowledging that there is no universally correct way to care. Searching inevitably implies making mistakes, and we can always improve the quality of our actions. Accountability implies that we are willing to check 
our perceptions against those of others, especially of the ones who are dependent on our care, and of others who are implied in the caring process. It also implies the willingness to admit mistakes, and to apologize for misjudgements or harmful actions. This clears the ground for forgiveness and has the capacity to revive broken contacts and to enable individuals to continue their lives in inner peace.

\section{ATTENTION, EMPATHY, COMPASSION AND LOVE}

Attention is the rarest and purest form of generosity (Simone Weil). ${ }^{2}$

The description of these "attentive activities" enables me to make a distinction between attention and other moral attitudes, which have been promoted as related to the first phase of care.

The first of these is empathy. Empathy is usually described as the ability and the willingness to stand in the shoes of the other. This attitude is indeed important in preventing what I have called "moral blindness" and what Joan Tronto has called "wilful neglect". The notion of empathy has however some serious drawbacks that underline the need to distinguish it from active attention.

Firstly it is a sheer impossibility to stand in the shoes of another, and this is certainly so when we acknowledge the principle of plurality. Secondly, the invitation to stand in the shoes in the other is in itself rather empty. It does not explain what we have to do once we have arrived there. In moving to the shoes of the other we again run the risk of bringing our own preconceptions with us. Or - conversely - we can also over-identify with the stories and the needs of the other, by which empathy can easily turn into pity.

My proposals for the different attentive activities are aimed exactly at countering these risks. Active attention supposes willingness for sustaining relationship, communication and interaction, but it can at the same time only thrive through respecting differences and boundaries and through distinguishing responsibilities.

The second related attitude is compassion, which is usually described as the ability to feel with the other, and especially to feel her or his suffering. Again, we cannot underestimate the importance of compassion as a moral attitude. It makes us sensitive for the pain people suffer and makes us aware of the hurt that we can inflict on one another, individually and collectively, and thus also of the need for care. Practising compassion has the capacity of enhancing understanding and respect for the lives of others and to take care of deprived persons. But also here is a "but". Compassion as a moral injunction to feel the other's suffering can lead to a fixating of victimhood and even its glorification, and thus to the diminution or the denial of responsibility. 
That is exactly what differentiates it from active attention. Active attention does not proceed from a preconceived idea about what we will discover when we engage in it. Attention may reveal suffering, but it can also bring up unexpected capabilities and desires in the other, like a longing for freedom, or a capability for self-care or a long forgotten capacity for pleasure and playfulness. When we accept flourishing as the overall goal of care, we should not undermine it from the outset with an obligation to concentrate on suffering and harm.

The third related moral attitude is unconditional love, the moral injunction to give love without expectations or conditions of a return. Although unconditional love can in my view be an important part of the caring process, I would not want to argue for equating it with attention. Again, attention is a more neutral attitude that should not be burdened with the expectation of specific outcomes. Loving is not always the best choice for action, and certainly not when it blurs the distinctions between self and other. As the saying goes: love can make blind. The notion of unconditional love has however an undeniable quality that we can transfer to active attention, and that is exactly its unconditionality. I can best explain this by introducing different notions of reciprocity.

Many acts of attention and caregiving are based on - often unreflected - notions of exchange: I give you something (in this case attention) because I can then expect something similar from you in return. Elsewhere I have called this attitude "exchange reciprocity". We can however also use a more refined notion of reciprocity: I give you my attention and care because I see you need it, and I am ready to give it for free, without expectation of a return. It is giving for the sake of giving. We need not to be worried to remain empty-handed. Giving for the sake of giving sets something in movement and we will probably get a return from a direction we had not expected. For many care givers the flourishing of the care receivers is often a major return in itself.

It is in giving that we receive, as the great Francis of Assisi said. Following his advice, attentive love can become a habit or a disposition, something we live and give, independently from expectations of a return. When it becomes a habit, attentive love can also be expanded more easily to include ourselves, animals, nature and even the world. In the spiritual tradition of the Andes this is referred to as the principle of Munay, which means love under your will, or conscious loving.

\section{ATTENTION AND TAKING CARE OF}

Energy flows where attention goes (James Redfield 1997).

We now are hopefully able to appreciate that active attention is a prerequisite for the second 
phase of care, taking care of, and the taking of responsibility that caring needs are met. By engaging in active attention, we develop the capability to see if care is needed and in what form. Again taking recourse to etymology may be helpful here. The word responsibility literally refers to the ability to respond, the ability to give an answer. The activity of responsibility thus involves assuring oneself to respond to a need for care in the appropriate manner. At the same time it may be clear that the activities of attending and responding cannot always be neatly separated. Much attention in fact takes place when we are responding to a need or when we engage in the actual care giving, the third element of care. This is why I prefer the terms "elements" or "dimensions of care" above the term "phases of care" that suggests a sequence in time.

My granddaughter was right: attention is something we give during our interactions and the things we do together. This goes not only for children, but also for the care for frail elderly persons, who are dependent on the care of others for the fulfilment of their daily needs. Of course it is possible to wash, cloth or feed a dependent elderly person without attention. But in that case the washing, clothing and feeding become just work, an activity that lacks a deeper meaning for both the giver and receiver. It is the attention and the meaningful human interactions that make these activities into caring work, and it is exactly this mixture that enhances human flourishing.

Sometimes also attention in itself will be enough for care to take place. If we want to understand this we only have to bring into our awareness those occasions when just listening or being present is enough. Often it is only our listening that enables the other to think about what he or she can best do. The listening then supports the capacity for self-care. But it can also be that in this particular case further action does not belong to our responsibility, or that acting would undermine the responsibility or wellbeing of the other. Active attention may, in short, also convince us of the need for refraining from further action.

\section{RENDERING CARE THE MEANING OF POLITICS}

Thus far it might seem that active attention as I have described it requires close proximity between the attender and the attended. That would limit its applicability to what has been called "the private" or the personal, and would thus position it outside of politics. In many cases indeed attention works at its best in situations of close proximity, like in friendship, nursing, therapy and counselling. But maybe we can see these practices as exemplary for caring situations where more distance is implied, and thus also as examples for citizenship practices. They may prepare their participants for practicing attention at a larger scale, also for persons they do not know personally.

Many situations in politics require indeed careful attention to those affected by public debate and political measures. Many of the attentive activities that I listed are useful here, and their application will make a difference compared to a politics that does not listen to their voice. We 
only have to think of the issues of survivors of assault or sexual abuse, or of the users of public housing and public transport to understand this. And here too practices like "waiting" and attentive listening are important. Nothing is so easy - especially in the age of mass media - as to automatically join the waves of public indignation, or the spectres of supposed enemies, or to be indifferent towards people whom we do not know but need our solidarity and support. We need more collective reflection on this phenomenon. It is my hope that the notion of active attention as attention at its best may contribute towards rendering care the meaning of politics.

\section{ACKNOWLEDGEMENT}

I presented an earlier version of this paper on the conference "La Qualità del Welfare: la tutela degli anziani”, Rimini 18-19 September 2013. With thanks to the organizers for inviting me to speak, and to the audience for the positive feedback on what I have to say. Thanks also to Myschka Mellenbergh, Louise Du Toit, Joan Tronto and Margo Kistemaker for their comments on the first version. The current version of this paper was presented for the conference "A meaningful life in a just society. Investigating Wellbeing and Democratic Caring" at which I was a member of a panel on "Rendering care the meaning of politics", Utrecht, Universiteit voor Humanistiek, 30-31 January 2014.

\section{NOTE}

1. The aspect of waiting may make us realize that many situations in life require an "active passive" stance, like receiving and acknowledging, or like the attentive waiting of the waiter in the restaurant. With thanks to Louise Du Toit for pointing this out to me.

2. From an April 13, 1942 letter to poet Joë Bousquet, published in their collected correspondence Correspondance 1982: 18. Lausanne: Editions l'Age d'Homme.

\section{REFERENCES}

Barad, K. 2007. Meeting the universe halfway: Quantum physics and the entanglement of matter and meaning. Durham: Duke University Press.

Barnes, M. 2012. Care in everyday life: An ethic of care in practice. Bristol: Policy Press, Bristol.

Boulous Walker, M. 2016. Slow philosophy: Reading against the institution. London: Bloomsbury.

Bozalek, V. 2017. Slow scholarship in writing retreats: A diffractive methodology for response-able pedagogies. South African Journal of Higher Education 31(2): 40-57.

Bozalek, V. and M. Zembylas. 2017. Towards a response-able pedagogy across higher education institutions in post-apartheid South Africa: An ethico-political analysis. Education as Change 21(2): $62-85$.

Despret, V. 2016. What would animals say if we asked the right questions. Minneapolis: University of Minnesota Press.

Haraway, D. 2016. Staying with the trouble: Making kin in the Chthulucene. Durham and London: Duke University Press.

Lenz Taguchi, H. 2012. A diffractive and Deleuzian approach to analysing interview data. Feminist 
Theory 13(3): 265-281.

Miller, H. 1962. Stand still like the hummingbird. New York: New Directions.

Redfield, J. 1997. The Celestine prophecy: An adventure. New York: Grand Central Publishing.

Rose, D. B. 2013. Val Plumwood's philosophical animism: Attentive interactions in the Sentient World. Environmental Humanities 3(1): 93-109. doi: https://doi.org/10.1215/22011919-3611248

Sevenhuijsen, S. 1998. Citizenship and the ethics of care: Feminist considerations on justice, morality, and politics. London and New York: Routledge.

Sevenhuijsen, S. 1999. Too good to be true? Feminist considerations about trust and social cohesion, Focaal, Tijdschrift voor Antropologie 34: 207-222.

The Essential Rumi. 1995. Translated by Coleman Barks with John Moyne, A. J. Arberry and Reynold Nicholson.

Tronto, J. C. 1993. Moral boundaries: A political argument for an ethic of care. London and New York: Routledge. 